\title{
Photoluminescence of silver in glassy matrices
}

\author{
M. A. García ${ }^{a)}$ \\ Instituto de Magnetismo Aplicado "Salvador Velayos," P.O. Box 155, 28230 Las Rozas, Madrid, Spain \\ M. García-Heras, E. Cano, J. M. Bastidas, and M. A. Villegas \\ Centro Nacional de Investigaciones Metalúrgicas, CSIC, Avenida Gregorio del Amo, 8, \\ 28040 Madrid, Spain \\ E. Montero and J. Llopis \\ Departamento de Física de Materiales, Faultad de Ciencias Físicas, Universidad Complutense de Madrid, \\ Avenida Complutense s/n, 28040 Madrid, Spain \\ C. Sada, G. De Marchi, G. Battaglin, and P. Mazzoldi \\ Dipartimento di Fisica, INFM, Università di Padova, via Marzolo 8, 35131 Padova, Italy
}

(Received 15 March 2004; accepted 10 June 2004)

This work studies the behavior of $\mathrm{Ag}^{+}$ions incorporated in different silica-based glassy matrices. To this end, Ag-doped silica coatings, prepared via sol-gel and deposited on pure silica and soda-lime glasses, are investigated by means of structural and optical spectroscopy techniques. Silver tends to segregate towards the interface during the annealing process, but in the case of soda-lime glassy substrates the exchange process favors its diffusion into the substrate. The environment of $\mathrm{Ag}^{+}$ions during the annealing process determines their final oxidation state. In the pure silica matrix, $\mathrm{Ag}^{+}$ ions are found to be unstable and tend to reduce to $\mathrm{Ag}^{0}$, with the subsequent formation of metallic nanoparticles. However, the presence of network formers and modifiers gives rise to the appearance of nonbridging oxygen, which allows the stabilization of $\mathrm{Ag}^{+}$ions in the matrix. () 2004 American Institute of Physics. [DOI: 10.1063/1.1778473]

\section{INTRODUCTION}

In recent years, growing attention has been paid to the techniques of metal incorporation in glassy matrices, in view of the optical properties that can be obtained. ${ }^{1-10}$ For instance, the incorporation of isolated metal ions (mainly $\mathrm{Ag}^{+}$ and $\mathrm{Cu}^{+}$) in glass gives rise to an intense photoluminescence (PL) emission, which is potentially useful for optoelectronic applications, and a concurrent change in the refraction index with the consequent formation of light waveguides. ${ }^{11-20} \mathrm{On}$ the other hand, the metal ions may be reduced, causing them to aggregate and form metal nanoparticles that exhibit other interesting optical properties such as high nonlinear susceptibility, optical absorption ascribed to plasmon resonances, and so on. ${ }^{1,9,21-25}$ In both cases the matrix plays a crucial role in controlling the metal oxidation/reduction processes and, thus, the final properties of the system. It is interesting to note that PL emissions from $\mathrm{Ag}^{+}$ions in glassy matrices can shift from UV to the VIS-green region of the spectrum depending on the composition of the matrix. ${ }^{12,15-20}$

This work addresses the kinetics of $\mathrm{Ag}$ ions in glassy matrices and the interaction between these ions and their environment, determining the parameters that control diffusion, oxidation/reduction, and aggregation processes and therefore the optical response of the system. For this purpose, Ag-doped silica coatings were prepared via sol-gel on pure silica and soda-lime substrates and subjected to different annealing processes. In this way we attempt to study the evolution of optical properties as silver diffuses from the

\footnotetext{
a) Author to whom correspondence should be addressed; electronic mail: miguelag@renfe.es
}

coating to the substrate, and thus its interaction with the environment.

\section{EXPERIMENT}

Thin silica glass films doped with silver $\left(\mathrm{SiO}_{2}: \mathrm{Ag}\right)$ were prepared by a sol-gel dip-coating method. The starting solutions, with a final composition of $99 \mathrm{SiO}_{2} \cdot 1 \mathrm{Ag}(\mathrm{mol} \%)$, were prepared using silicon tetramethoxide, silicon methyltriethoxide, and $\mathrm{AgNO}_{3}$ as precursors. Hydrolysis was carried out at $p \mathrm{H} \sim 2$ using $\mathrm{HNO}_{3}$ as the catalyst and $\mathrm{CH}_{3} \mathrm{OH}$ as the solvent. The TMOS:MTES: $\mathrm{CH}_{3} \mathrm{OH}: \mathrm{H}_{2} \mathrm{O} \cdot\left(\mathrm{HNO}_{3}\right): \mathrm{H}_{2} \mathrm{O}_{2}$ molar ratio used to prepare the sols was 1:1:14:5:1. Hydrogen peroxide was added as an oxidizing agent in order to preserve the silver as $\mathrm{Ag}^{+}$, thus preventing the formation of metal silver particles and favoring its incorporation in the gel network as $\mathrm{Ag}^{+}$. The sols were colorless and without any precipitate, which indicates that silver was present as $\mathrm{Ag}^{+}$in the matrix. The films were deposited on pure silica and commercial soda-lime glass slides by dipping the previously cleaned slides into the solution and lifting them out by means of a motor operating at a constant speed in order to ensure thickness homogeneity. The samples were then dried at $60{ }^{\circ} \mathrm{C}$ for $5-10 \mathrm{~min}$ and subsequently heated for $1 \mathrm{~h}$ in air at different temperatures between 60 and $500{ }^{\circ} \mathrm{C}$. The coating thickness varied between 200 and $400 \mathrm{~nm}$. No clear dependence of coating thickness on the annealing temperature was found, although the thickest coatings were seen to correspond to intermediate annealing temperatures. In order to promote the diffusion of silver to the substrate, one sample prepared on a silica substrate and annealed at $500{ }^{\circ} \mathrm{C}$ was subsequently reannealed at $1000{ }^{\circ} \mathrm{C}$ for $1 \mathrm{~h}$. 


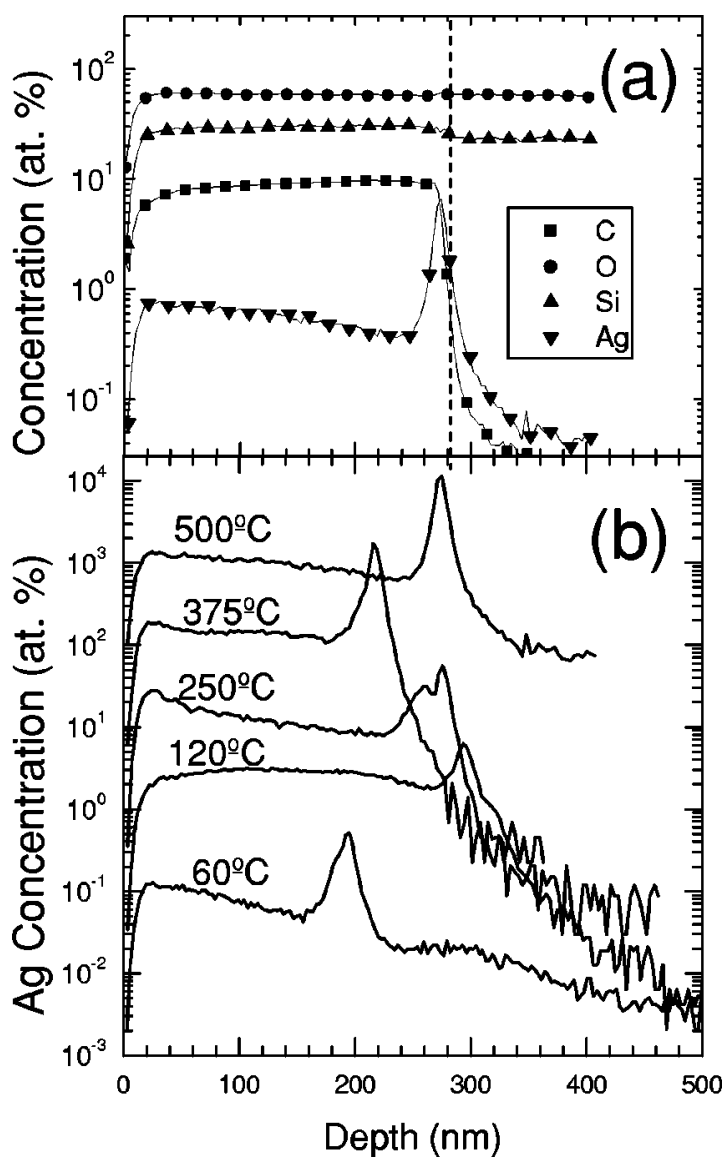

FIG. 1. (a) SIMS concentration profile (normalized according to RBS data) for Ag-doped silica coating deposited on pure silica substrate and annealed at $500{ }^{\circ} \mathrm{C}$. Dashed line indicates the coating-substrate interface. (b) Silver concentration profiles for coatings deposited on pure silica glass and annealed in air at different temperatures.

Rutherford backscattering spectroscopy (RBS) measurements were carried out using a $4 \mathrm{He}^{+}$beam at energy of 2.2 MeV. Secondary ion mass spectra (SIMS) measurements were performed by negative secondary ion detection using a $10 \mathrm{KV} \mathrm{Cs}^{+}$primary beam (the sample potential was fixed at $+4.5 \mathrm{KV}$ ) with final impact energy of $14.5 \mathrm{KeV}$. X-ray photoemission spectroscopy (XPS) analysis was performed using a VG Microtech model MT 500 spectrophotometer with a $\mathrm{Mg} K \alpha_{1.2}$ anode $\mathrm{x}$-ray source $(h \nu=1253.6 \mathrm{eV})$, with primary beam energy of $15 \mathrm{kV}$ and an electron current of $20 \mathrm{~mA}$. In order to remove surface contamination, $\mathrm{Ar}^{+}$-ion sputtering was carried out for 5 min with primary beam energy of $5 \mathrm{kV}$ and an ion intensity of $10 \mathrm{~mA}$. PL excitation (EX) and emission (EM) spectra were performed using a Perkin-Elmer LS-5 spectrofluorometer. This device provides corrected EX and EM spectra in the 230-700 and $250-720 \mathrm{~nm}$ ranges, respectively.

\section{RESULTS}

\section{A. Structural characterization}

Figure 1(a) shows concentration profiles for a coating deposited on silica annealed at $500{ }^{\circ} \mathrm{C}$ (measured by SIMS and normalized according to RBS data). As may be expected, the $\mathrm{Si}$ and $\mathrm{O}$ concentrations are almost constant throughout

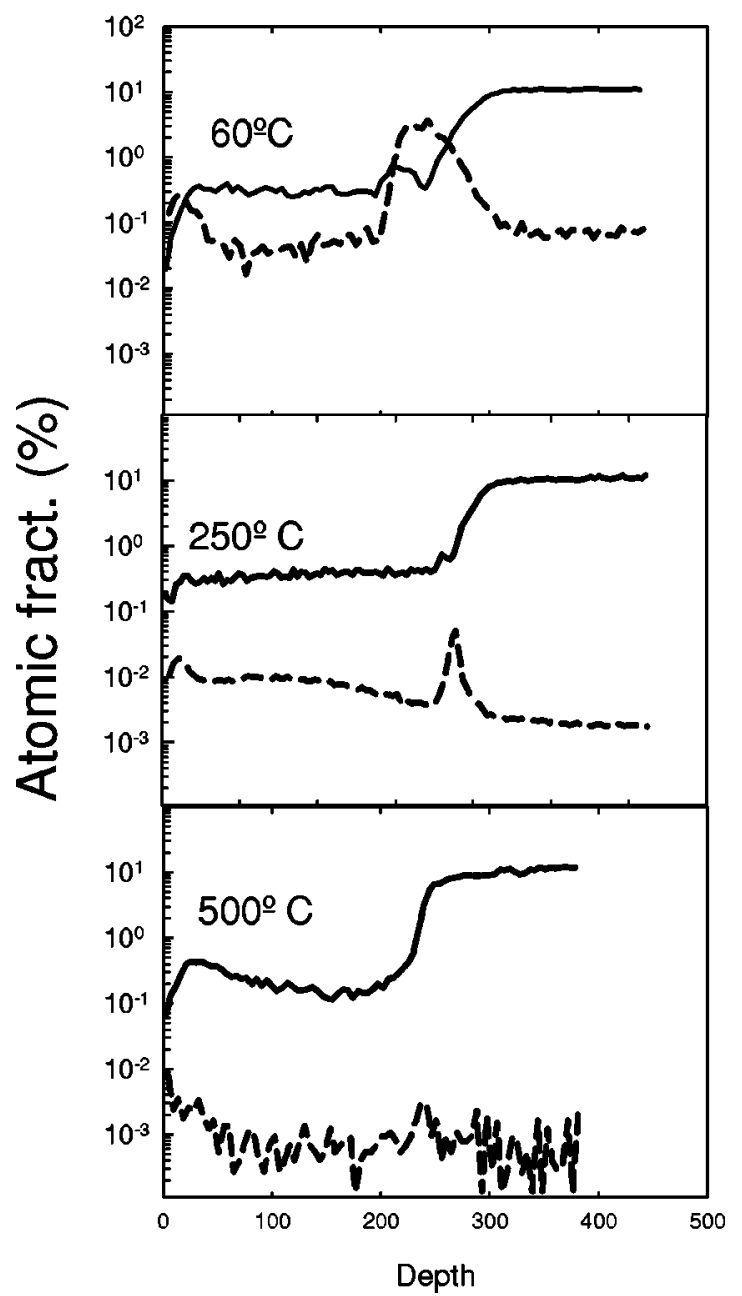

FIG. 2. Ag (dashed line) and Na ( solid line) SIMS concentration profiles (normalized according to RBS data) for coatings deposited on soda-lime glass substrates and annealed at different temperatures.

the deposited layer. Besides, a large amount of carbon impurities from the residual metal-organic precursors remain in the coating after annealing ( $\sim 9 \%$ atomic fraction). This concentration is almost constant for all the samples annealed at different temperatures in the $60-500{ }^{\circ} \mathrm{C}$ range. Near the coating surface the silver concentration is about 0.8 at. $\%$, and at the interface there is a segregation peak at around $\sim 6$ at. $\%$, irrespective of the annealing temperature [see Fig. 1(b)]. The coating-substrate interface is not sharp and partial silver in-diffusion can be observed. Furthermore, as the annealing temperature rises, the amount of silver present in the coating is seen to diminish, while the amount of silver in the substrate (beyond the segregation peak) rises. RBS measurements also indicate silver segregation in a $\sim 20 \mathrm{~nm}$ thick layer at the outer surface of the coating.

A completely different behavior is found for the coatings deposited on soda-lime glassy substrates. Figure 2 displays $\mathrm{Ag}$ and $\mathrm{Na}$ concentration profiles for the coatings annealed at different temperatures. It can be seen that most of the silver segregates near the interface and the total amount of silver in the analyzed region decreases as the annealing temperature rises. Carbon impurities are also found in the coatings in this case, with an equivalent concentration to those deposited on silica substrates. 

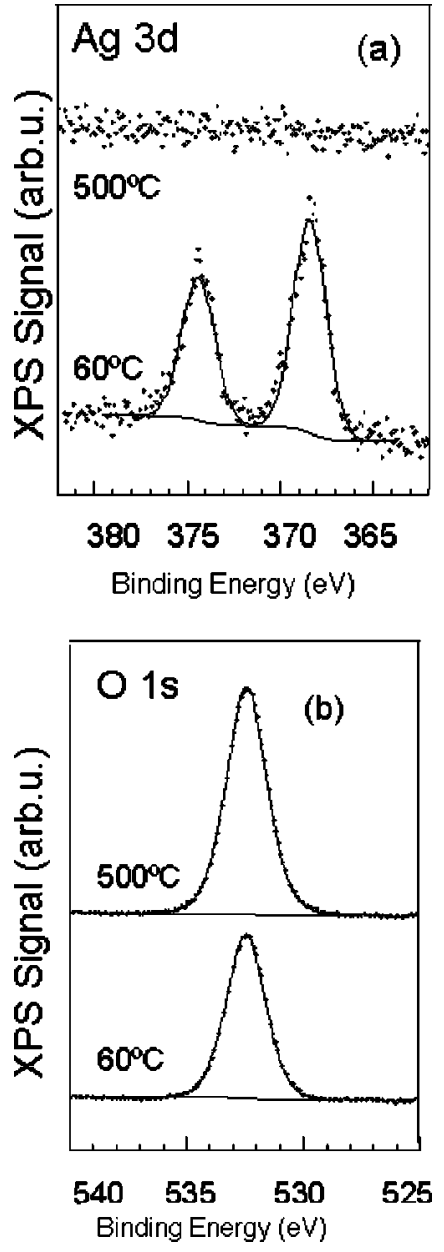

FIG. 3. XPS spectra for coatings deposited on pure silica glass and annealed at 60 and $500{ }^{\circ} \mathrm{C}$ after $5 \mathrm{~min}$ of $\mathrm{Ar}^{+}$-sputtering, showing (a) $\mathrm{Ag} 3 d$ corelevel and (b) $\mathrm{O} 1 s$ level core emissions.

XPS analysis confirms the presence of $\mathrm{Si}, \mathrm{O}, \mathrm{Ag}, \mathrm{Na}$, and $\mathrm{C}$ in the coatings. Spectra for the samples before and after 5 min of $\mathrm{Ar}^{+}$sputtering show similar features, except for a decrease in the $\mathrm{C} 1 s$ signal due to the removal of surface contamination. Figure 3(a) shows the Ag $3 d$ core-level emission corresponding to coatings deposited on silica substrates and annealed at different temperatures after $5 \mathrm{~min}$ of $\mathrm{Ar}^{+}$-ion sputtering. For the coating annealed at $500{ }^{\circ} \mathrm{C}$, no peak related to the presence of silver is observed, whereas the spectrum corresponding to the coating annealed at $60{ }^{\circ} \mathrm{C}$ exhibits the $\mathrm{Ag} 3 d$ doublet clearly defined at $368.4 \mathrm{eV}$ binding energy. The position of these peaks indicates that silver is present as $\mathrm{Ag}^{0}(368.3 \mathrm{eV})$ and not as $\mathrm{Ag}_{2} \mathrm{O}(367.8 \mathrm{eV})$ or $\mathrm{AgO}(367.4 \mathrm{eV}) .^{26}$ The absence of oxidized silver is confirmed by the oxygen spectra. Figure $3(\mathrm{~b})$ shows the $\mathrm{O} 1 \mathrm{~s}$ core-level emission corresponding to the same samples. Both present similar O $1 \mathrm{~s}$ spectra, showing a well-defined peak only at $532.4 \mathrm{eV}$, which can be attributed to $\mathrm{SiO}_{2}$. Emissions from silver oxides (located at $\sim 529.4 \mathrm{eV}$ for $\mathrm{Ag}_{2} \mathrm{O}$ and at $\sim 528.4 \mathrm{eV}$ for $\mathrm{AgO}$ ) are completely absent.

\section{B. Optical properties}

Irrespective of the substrate and annealing temperature, all the as-prepared coatings are transparent and the optical

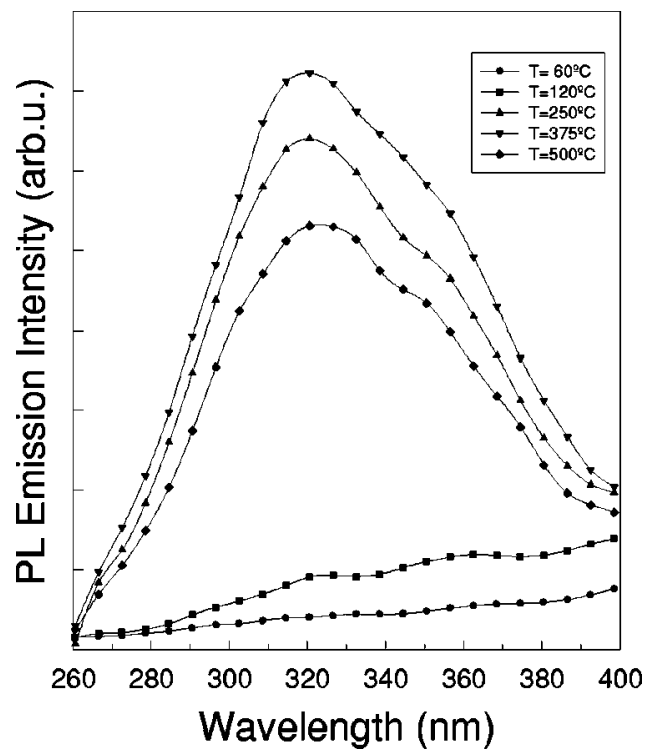

FIG. 4. PL emission spectra for coatings prepared on soda-lime substrates upon photoexcitation with $228 \mathrm{~nm}$ light, annealed at different temperatures.

absorption spectra do not show the $410 \mathrm{~nm}$ band characteristic of silver nanoparticles. ${ }^{1,9}$ However, after two months of ageing the coatings prepared on silica substrates exhibit a faint yellowish coloring characteristic of Ag-cluster formation.

The Ag-doped coatings deposited on silica substrates do not exhibit any luminescence besides that already observed and reported for pure silica coatings, ${ }^{9,27}$ which is characterized by an intense PL emission band centered at about $370 \mathrm{~nm}$. In contrast, the coatings prepared on soda-lime substrates present an intense emission band centered at about $320 \mathrm{~nm}$ upon photoexcitation with UV light, as can be seen in Fig. 4. The excitation spectra corresponding to this emission exhibit a peak centered at about $228 \mathrm{~nm}$, which has already been reported. ${ }^{9}$ This band has previously been ascribed to the presence of $\mathrm{Ag}^{+}$ions in glassy matrices. Its intensity increases in line with the annealing temperature up to $375{ }^{\circ} \mathrm{C}$, but decreases at $500{ }^{\circ} \mathrm{C}$.

The absence of PL emissions in the coatings deposited on silica substrates may in principle be ascribed to the presence of $\mathrm{Ag}^{0}$ (pointed out by XPS results). However, there is another possible explanation that needs to be ruled out, based on the presence of many residual $\mathrm{OH}$ groups from the precursors present in the glassy network when the matrix is annealed at temperatures below $1000{ }^{\circ} \mathrm{C}$. The energetic vibrational modes of these groups may provide a nonradiative deexcitation path. In order to verify this possibility, a coating deposited on a silica substrate and annealed at $500{ }^{\circ} \mathrm{C}$ was subsequently reannealed at $1000{ }^{\circ} \mathrm{C}$ for $1 \mathrm{~h}$ in air. After this treatment the sample remained transparent and SIMS measurements showed that there was no silver in the coating but that it had passed into the substrate. Neither in this case PL emissions characteristic from silver were observed.

\section{DISCUSSION}

All the as-prepared coatings are transparent, confirming that no silver nanoparticles larger than $1 \mathrm{~nm}$ diameter are 
formed and that silver is probably dispersed in an atomic state in the glassy network, in the case of both silica and soda-lime glass substrates.

For soda-lime substrates, SIMS results confirm that even at low annealing temperatures the silver content is significantly lower than that found in silica substrates, and a detectable diffusion of silver into the substrate can be observed. Silver diffusion from the coatings on soda-lime glass substrates is favored by the ion exchange process, which also occurs at low temperatures, between $\mathrm{Ag}^{+}$in the coating and $\mathrm{Na}^{+}$in the substrate, with the subsequent interdiffusion of the two species in order to maintain the electrical neutrality of the glass. ${ }^{4,5,8}$ This result is consistent with the PL spectra, which exhibit the emission band characteristic of the presence of $\mathrm{Ag}^{+}$. With silica substrates, the silver concentration gradient may be the main driving force for silver diffusion from the coating to the substrate. Furthermore, because the silver diffusion coefficient in silica is lower than in soda-lime glass, ${ }^{28}$ more thermal energy is required to observe an appreciable diffusion of silver into the silica substrate. Segregation to the interface is observed with both the silica and soda-lime substrates, indicating that this process is characteristic of the coating and independent of the substrate. This concentration peak may be ascribed to defects at the interface related with the preparation method.

As far as the optical properties of the coatings are concerned, $\mathrm{Ag}^{+}$ions are known to be luminescent in both crystalline and glassy matrices. In particular, for silica-based glassy matrices, emission takes place between 300 and $450 \mathrm{~nm}$, depending on the network nature and composition. $^{5-14}$ In contrast, no PL emission due to $\mathrm{Ag}^{0}$ atoms has been reported to the best of our knowledge.

In the case of coatings prepared on silica substrates, XPS measurements confirm that silver is present as $\mathrm{Ag}^{0}$ and that no $\mathrm{Ag}^{+}$is detected in the coating. As may be expected, no PL signal characteristic of $\mathrm{Ag}^{+}$ions is detected for those samples. Moreover, since a yellowish coloring is observed two months after their preparation, it is suggested that the $\mathrm{Ag}^{+}$ions in these coatings are unstable, being mainly reduced during annealing even at low temperatures $\left(60^{\circ} \mathrm{C}\right)$. Both the higher silver concentration in the coatings deposited on silica substrates and the evidence that $\mathrm{Ag}^{0}$ diffuses much more easily than $\mathrm{Ag}^{+}$(Ref. 28) can explain the nucleation and growth of nanoparticles and the yellowish coloring shown by these samples after two months of ageing.

For the coatings deposited on soda-lime substrates, the increase in the PL emission with the annealing temperature (up to $375^{\circ} \mathrm{C}$ ) is directly correlated with the increase in $\mathrm{Ag}$ atoms that diffuse towards the soda-lime substrate during the process (see Fig. 2). Since the $\mathrm{Ag}^{0}$ atoms that remain in the coating after the annealing process are $\mathrm{Ag}^{0}$ (for these atoms the substrate is irrelevant), the $\mathrm{Ag}^{+}$ions that cause the luminescence must be in the substrate or at the interface. The decrease in PL intensity observed for the sample annealed at $500{ }^{\circ} \mathrm{C}$ is correlated both to the lowering of the silver concentration and the start of a thermally activated reduction of silver.

The main difference between pure silica glass and silicabased glasses is the presence in the latter case of network modifiers (such as $\mathrm{Ca}$ and $\mathrm{Na}$ for soda-lime glasses). These elements generate nonbridging oxygen, with nonsaturated bonds, which should act as pinning centers for the $\mathrm{Ag}^{+}$ions, therefore favoring their stability. As has already been mentioned, several studies have shown that the PL emission ascribed to Ag-doped glasses appears in different regions of the spectrum depending on the glass composition and the type of network formers/modifiers, supporting the idea that $\mathrm{Ag}^{+}$ions must be close to these atoms, and hence that they modify the $\mathrm{Ag}^{+}$energy levels and shift the PL emissions. We therefore propose that silver atoms in pure silica networks are stable only as $\mathrm{Ag}^{0}$ atoms, and not as $\mathrm{Ag}^{+}$. The presence of nonbridging oxygen (generated by the network modifiers) is necessary to allow the stabilization of $\mathrm{Ag}^{+}$ions, which yield to PL emission in the UV, and this is why PL emissions from silver in pure silica substrates are not reported in the literature. In this respect, Pivin recently found a very faint PL emission from $\mathrm{Ag}^{+}$in pure silica ${ }^{29}$ in $\mathrm{Ag}$-implanted samples (the implantation process can break some bonds, creating nonbridging oxygen). Furthermore, PL measurements with time resolution carried out on silver ruby glass ${ }^{30}$ pointed towards a possible donor-acceptor pair that is responsible for PL emissions ascribed to the presence of $\mathrm{Ag}^{+}$in glasses.

\section{CONCLUSIONS}

In summary, it has been found that $\mathrm{Ag}^{+}$ions diffuse in pure silica matrices during annealing processes, being reduced to $\mathrm{Ag}^{0}$ and subsequently forming silver metallic nanoparticles, even in oxidizing atmospheres such as air. However, if there is a large amount of nonbridging oxygen in the glassy matrix (due to the presence of network formers/ modifiers) the $\mathrm{Ag}^{+}$ions bonded to this oxygen remain stable and give rise to their characteristic PL emission. Since silver atoms are pinned to the nonbridging oxygen (and are therefore close to the network modifiers), their PL properties are strongly dependent on the glass composition.

\section{ACKNOWLEDGMENT}

This research was supported by the Spanish Ministry of Science and Technology (Project No. MAT2002-04503-C0202).

${ }^{1}$ U. Kreibig and M. Vollmer, Optical Properties of Metal Clusters. Springer Series in Material Science Vol. 25 (Springer, Berlin, 1995).

${ }^{2}$ The Properties of Optical Glass, edited by H. Bach and N. Neuroth (Springer, Berlin, 1998)

${ }^{3}$ M. Mensnaoui, M. Maazaz, C. Parent, B. Tanguy, and G. Le Flem, Eur. J. Solid State Inorg. Chem. 29, 1001 (1992).

${ }^{4}$ S. E. Paje, J. Llopis, M. A. Villegas, and J. M. Fernández Navarro, Appl. Phys. A: Mater. Sci. Process. 63, 431 (1996).

${ }^{5}$ S. E. Paje, M. A. García, J. Llopis, M. A. Villegas, and J. M. Fernández Navarro, Appl. Phys. A: Mater. Sci. Process. 67, 429 (1998).

${ }^{6}$ E. Borsella, F. Gonella, P. Mazzoldi, A. Quaranta, G. Battaglin, and R. Polloni, Chem. Phys. Lett. 284, 429 (1998)

${ }^{7}$ A. A. Ahmed, N. A. Sharaf, M. H. Shaaban, and S. T. Abdel-Halim, Int. Cong. Glass 4, 503 (1992).

${ }^{8}$ E. Borsella, G. Battaglin, M. A. García, F. Gonella, P. Mazzoldi, R. Polloni, and A. Quaranta, J. Appl. Phys. 71, 125 (2000).

${ }^{9}$ M. A. Villegas, M. A. García, J. Llopis, and J. M. Fernández Navarro, J. Sol-Gel Sci. Technol. 11, 251 (1998).

${ }^{10}$ M. Mesnaoui, M. Maazaz, C. Parent, B. Tanguy, and G. Le Flem, Eur. J. Solid State Inorg. Chem. 29, 1001 (1992). 
${ }^{11}$ S. E. Paje, M. A. Garcia, J. Llopis, and M. A. Villegas, J. Non-Cryst. Solids 318, 239 (2003).

${ }^{12}$ J. H. Schulman, R. J. Ginther, C. C. Klick, R. S. Alger, and R. A. Levy, J. Appl. Phys. 22, 1479 (1951).

${ }^{13}$ N. N. Vil'chinskaya, A. V. Dmitryuk, E. G. Ignat'ev, G. T. Petrovskii, and O. C. Savvina, Sov. Phys. Solid State 26, 497 (1984).

${ }^{14}$ T. Findakly, Opt. Eng. 24, 244 (1985).

${ }^{15}$ R. V. Rawaswamy and R. Srivastava, J. Mod. Opt. 35, 1049 (1988).

${ }^{16}$ F. Seitz, Rev. Mod. Phys. 23, 328 (1951).

${ }^{17}$ G. P. Smith, J. Mater. Sci. 2, 139 (1967).

${ }^{18}$ R. J. Araujo, Contemp. Phys. 21, 77 (1980).

${ }^{19}$ A. V. Dmitryuk, N. D. Solov'eva, and N. T. Timofeev, Glass Sci. Technol. (Frankfurt/Main, Ger.) 68, 111 (1995).

${ }^{20}$ S. E. Paje, M. A. Garcia, M. A. Villegas, and J. Llopis, J. Non-Cryst. Solids 278, 128 (2000).

${ }^{21}$ P. Mazzoldi, G. W. Arnold, G. Battaglin, F. Gonella, and R. F. Haglund, J. Nonlinear Opt. Phys. Mater. 5, 285 (1996).

${ }^{22}$ H. Hövel, S. Fritz, A. Holger, U. Kreibig, and M. Vollmer, Phys. Rev. B
21, 18178 (1993).

${ }^{23}$ U. Kreibig, B. Schmitz, and H. D. Breuer, Phys. Rev. B 36, 5027 (1987).

${ }^{24}$ M. A. García, J. Llopis, and S. E. Paje, Chem. Phys. Lett. 315, 313 (1999).

${ }^{25}$ J. C. Pivin, M. A. García, H. Hofmeister, A. Martucci, M. Sendova Vassileva, M. Nikolaeva, O. Kaitasov, and J. Llopis, Eur. Phys. J. D 20, 251 (2002).

${ }^{26}$ D. Brigss and M. P. Seah, in Practical Surface Analysis, Auger an X-ray Photoelectron Spectroscopy Vol. 1, 2nd ed. (Wiley, Chichester, 1990), pp. 595-634.

${ }^{27}$ M. A. García, S. E. Paje, M. A. Villegas, and J. Llopis, Mater. Lett. 43, 23 (2000).

${ }^{28}$ A. Miotello, G. De Marchi, G. Mattei, P. Mazzoldi, and A. Quaranta, Appl. Phys. A: Mater. Sci. Process. A70, 415 (2000).

${ }^{29}$ J. C. Pivin (Private communication).

${ }^{30}$ S. E. Paje, J. Llopis, M. A. Villegas, M. A. García, and J. M. FernándezNavarro, Appl. Phys. A: Mater. Sci. Process. A67, 429 (1998). 